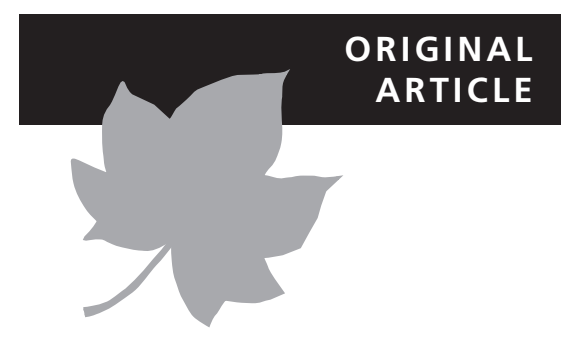

\title{
Past, present and future refugia for Tasmania's palaeoendemic flora
}

Karel Mokany ${ }^{1 \star}$, Greg J. Jordan ${ }^{2}$, Thomas D. Harwood ${ }^{1}$, Peter A. Harrison ${ }^{2}$, Gunnar Keppel ${ }^{3}$, Louise Gilfedder ${ }^{4}$, Oberon Carter $^{5}$ and Simon Ferrier ${ }^{1}$

${ }^{1}$ CSIRO, PO Box 1700, Canberra, ACT 2601, Australia, ${ }^{2}$ School of Biological Sciences, University of Tasmania, Private Bag 55, Hobart, Tas. 7001, Australia, ${ }^{3}$ School of Natural and Built Environments, University of South Australia, Adelaide, SA, Australia, ${ }^{4}$ School of Land and Food, University of Tasmania, Private Bag 78, Hobart, Tas. 7001, Australia, ${ }^{5}$ Natural and Cultural Heritage Division, Department of Primary Industries, Parks, Water \& Environment, Hobart, Tas., Australia

${ }^{*}$ Correspondence: Karel Mokany, CSIRO, PO Box 1700, Canberra, ACT 2601, Australia. E-mail: karel.mokany@csiro.au

\section{ABSTRACT}

Aim Refugia under past climates have been important in structuring current patterns in diversity, while refugia under anthropogenic climate change will likely be important in retaining this diversity and shaping new patterns. However, few studies have examined the congruence of past, present and future refugia, or the spatiotemporal connectivity of these refugia. Our aim was to test the extent of overlap of refugia under Last Glacial Maximum (LGM), present (2015) and likely future climates (2100), for Tasmania's palaeoendemic flora. We then aimed to identify areas of high spatiotemporal refugia connectivity, as priority areas for conservation and management.

Location Tasmania, Australia.

Methods We developed and applied a new community-level approach to identifying refugia, based on generalized dissimilarity modelling of compositional turnover and a set of reference sites with known biodiversity value. Using these projections of palaeoendemic plant refugia for past, present and future climates, we developed and applied a second approach to quantify the level of connectivity of these refugia over space and time.

Results Although there was large overlap (85\%) between current and future climates in the distribution of the highest value palaeoendemic refugia, the small congruence of these areas with refugia at the LGM resulted in only a small area $\left(c .9 \mathrm{~km}^{2}\right)$ of persistent high value refugia over all three time periods. Despite this, our spatiotemporal analysis identified several areas of high connectivity in refugial environments for Tasmania's palaeoendemic flora over time.

Main conclusions The community-level approaches we demonstrate here to quantify refugia and their spatiotemporal connectivity have the potential to advance our understanding of biodiversity dynamics, particularly for taxonomic groups that are species-rich, poorly studied or comprised of many rare species, where species-level approaches are less suitable.

\section{Keywords}

biodiversity, climate change, community, composition, connectivity, dissimilarity, endemism, phylogeny, plant, rarity

\section{INTRODUCTION}

Given the increasing threats facing biodiversity (Pimm et al., 2014), identifying areas that act as refugia under changing environmental conditions is becoming ever-more important. Refugia are habitats that biodiversity can retreat to, persist within, and potentially expand from, under changing climatic

(c) 2016 John Wiley \& Sons Ltd conditions (Loarie et al., 2008; Keppel et al., 2012). Identifying, protecting, and appropriately managing important areas of refugia is likely to be vital in maintaining biodiversity over the long-term (Klein et al., 2009; Reside et al., 2014).

Historically, ecologists have focussed on understanding and predicting areas that may have acted as important refugia under past environmental change (Bennett \& Provan, 
2008; Keppel et al., 2012). This research has highlighted the importance of past refugial areas in shaping current patterns in biodiversity, in terms of the distribution of species, centres of endemism, speciation events and phylogenetic uniqueness (Carnaval et al., 2009; Davies et al., 2009; Graham et al., 2010; Rosauer et al., 2015). Identifying areas of likely refugia for biodiversity under past environmental fluctuations has harnessed a variety of ecological approaches, including combinations of genetic analyses, environmental suitability modelling and fossil/pollen analyses (Keppel et al., 2012; Hampe et al., 2013).

More recently, attention has moved to predicting which areas are likely to act as important refugia into the future, under anthropogenic climate change. Given that important refugia under a warmer future climate may well be different to areas that acted as refugia under cooler past climates (Ashcroft, 2010), substantial new research has been undertaken to identify climate change refugia. This research has primarily relied on projections of change in the distribution of individual species under climate change scenarios, to highlight areas likely to be important refugia for those species into the future (Gavin et al., 2014; Birks, 2015).

Surprisingly little research has examined geographical congruence of past, present and future refugia. Areas that are important refugia regardless of the directionality of environmental change (e.g. to cooler or warmer conditions), may be particularly important in harbouring unique elements of biodiversity (Hampe \& Jump, 2011; Weber et al., 2014), and in retaining this diversity over the long term. The relatively small number of studies addressing this question have primarily applied species distribution modelling (SDM) and assessed areas where the focal species are predicted to occur in the past, present and future (Espíndola et al., 2012; Terribile et al., 2012; Maiorano et al., 2013). Relatively simple subsequent assessments of distributional stability indicate that areas consistently acting as refugia can indeed be important for species population resilience (Yannic et al., 2014).

There remains significant scope for developing new approaches to quantifying and identifying areas that are likely to have high stability and connectivity of refugial environments under climatic changes of varying intensity and directionality. Approaches that move beyond correlative SDM projections as a basis for assessing long-term refugia stability and connectivity may be particularly valuable (Keppel et al., 2015). This is due to the uncertainties over species' fundamental niches, as well as the limited capacity for SDMs to be applied to the many rare species that are often a focus for conservation and likely to have stronger reliance on refugia for their persistence (Worth et al., 2014; Birks, 2015).

Here, we develop and demonstrate a new community-level approach for quantifying past, present, and future refugia, based on generalized dissimilarity modelling (GDM) (Ferrier et al., 2007) derived predictions of community compositional turnover. We then implement a new approach to assess the connectivity of predicted refugial areas over space and time. We apply these novel techniques to the palaeoendemic flora of Tasmania, a group of phylogenetically ancient and geographically restricted species (Jordan et al., 2016), identifying likely areas of refugia across Tasmania under the current climate, the projected climate at the Last Glacial Maximum (LGM - 21,000 years ago), and the projected future climate in 2100 under anthropogenic climate change. By identifying refugial areas with high spatiotemporal connectivity over past, present and future climates, we highlight priority areas for long-term conservation and management of Tasmania's unique palaeoendemic flora.

\section{MATERIALS AND METHODS}

\section{Past, present and future environments}

Our analyses focus on the island state of Tasmania, Australia (centred at $42^{\circ} 01^{\prime} \mathrm{S} ; 146^{\circ} 36^{\prime} \mathrm{E}$ ), an area of $c .68,000 \mathrm{~km}^{2}$, $77 \%$ of which is native vegetation (TASVEG 2.02009 ). For all the analyses, we applied $\mathrm{a} \approx 250 \mathrm{~m}\left(9^{\prime \prime}\right)$ resolution spatial grid over this region, as defined by the Australian GEODATA 9 Second Digital Elevation Model. To generate spatially complete environmental data for current conditions, we applied the $250 \mathrm{~m}$ digital elevation model of the study region in ANUCLIM (Xu \& Hutchinson, 2010), which for Tasmania accounts for slope and aspect in deriving fine-resolution climate data.

To derive environment layers relevant to future climate change, we applied bias-adjusted fine scale $\left(0.1^{\circ}\right)$ dynamically downscaled climate projections for 2100, from the Climate Futures for Tasmania project (Corney et al., 2010; Grose et al., 2010). The climate projections for 2100 were for the A2 SRES emissions scenario from two general circulation models (GCMs): CSIRO mk3.5 and MIROC3.2 (medres). The climate projections were further statistically downscaled in the present analysis to $250 \mathrm{~m}$ grid resolution using ANUCLIM 6.1 (Xu \& Hutchinson, 2010), again incorporating topographic effects on local climate. Both GCMs for this emissions scenario project relatively minor changes in annual precipitation for Tasmania $(+1$ and $+4 \%)$ but substantially warmer mean annual temperatures $\left(+3.2\right.$ and $\left.+2.8^{\circ} \mathrm{C}\right)$ (Fig. 1).

For environment layers relevant to the LGM, we applied projections from two GCMs provided by the Paleoclimate Modelling Intercomparison Project: CCSM and CNRM (Braconnot et al., 2012). Both GCMs project substantially cooler mean annual temperatures for Tasmania at the LGM $\left(-4.0\right.$ and $-1.5{ }^{\circ} \mathrm{C}$ ) (Fig. 1), but project a wetter LGM climate, in contrast to palaeological evidence that suggests Tasmania was drier at the LGM than present (Worth et al., 2014). We therefore applied the approach of Worth et al. (2014) of reducing the projected LGM precipitation for both GCMs to $75 \%$ of their original value, resulting in a projected LGM climate that was drier than current by $10.6 \%$ (CCSM) or $20.0 \%$ (CNRM) (Fig. 1). Climate projections for the LGM were downscaled to $1 \mathrm{~km}$ resolution, as described by Worth et al. (2014), and resampled to $250 \mathrm{~m}$ grid resolution, 

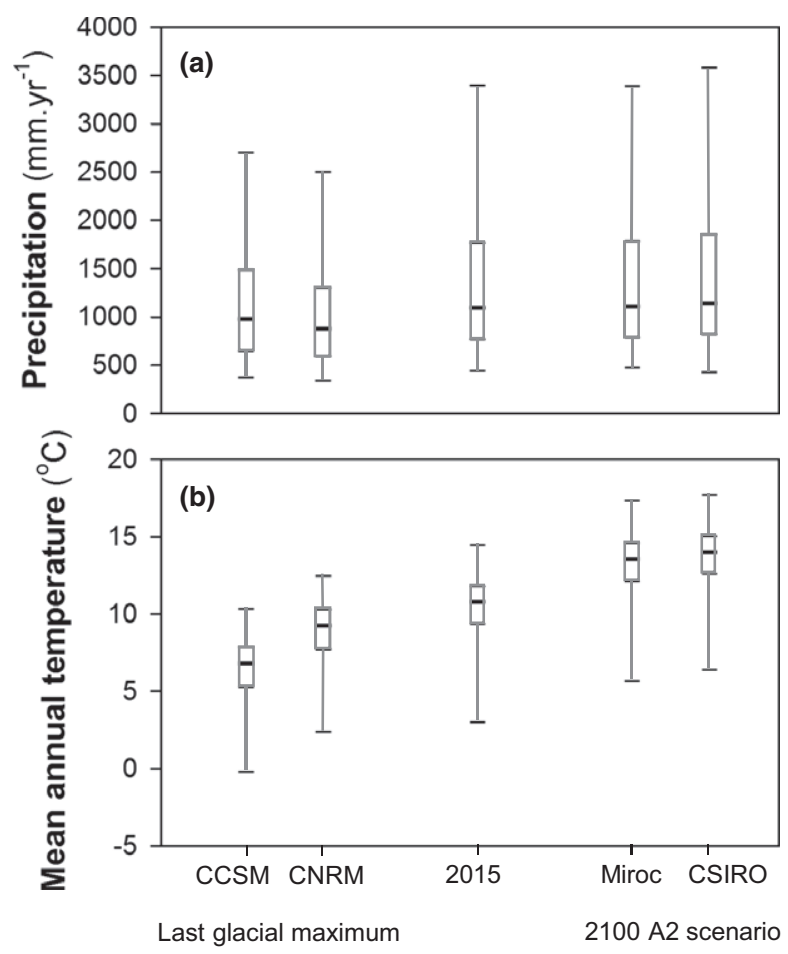

Figure 1 Mean annual precipitation (a), and mean annual temperature (b), for the present land area of Tasmania under two general circulation models (GCMs) for the Last Glacial Maximum (CCSM, CNRM), present (2015), and two GCMs at 2100 for the A2 climate change scenario (MIROC, CSIRO).

without incorporating local topography due to uncertainties in microclimatic effects at the LGM. Estimated permanent ice cover across Tasmania at the LGM was also obtained and applied (Barrows et al., 2002).

\section{Compositional dissimilarity modelling}

To model plant community compositional dissimilarity, we utilized the same data on plant community composition in Tasmania as applied previously for plant biodiversity modelling (Mokany et al., 2012, 2015). Specifically, the plant species composition of 175 grid cells across Tasmania was obtained by aggregating 562,772 occurrence point records of native plant species (2051 species, from 1970 to 2010) (Tasmanian Natural Values Atlas) to $250 \mathrm{~m}$ grid cells. A sampling function was then applied (Mokany et al., 2012) to select those grid cells with sufficient records to be deemed a 'community sample'. The resulting 175 grid cells were distributed across all Tasmania, adequately representing the wide range of environmental conditions present (Mokany et al., 2015). These 175 grid cells with community composition data were comprised of 1220 plant species in total, and were used to generate a site by site matrix of compositional dissimilarities, based on Sørensen's (1948) index.

These compositional dissimilarity data were combined with the spatial environmental data for current climate conditions to generate a revised model of pairwise plant community compositional dissimilarity, using GDM (Ferrier et al., 2007) within the 'gdm' package in $R$ (Manion et al., 2016; R Core Team, 2016). GDM accounts for non-linearities in both: (1) the rate of compositional turnover along environmental gradients, and; (2) the relationship between compositional dissimilarity and ecological distance in predicting compositional dissimilarity between site pairs as a function of the environmental conditions at each site (Ferrier et al., 2007). The model of compositional dissimilarity contained four environmental variables (annual precipitation, maximum temperature of the warmest period, minimum temperature of the coolest period, isothermality) plus geographical distance, with the significance of all variables assessed through a permutation test (1,000 repetitions) (see Appendix S1 in Supporting Information). Substrate variables were not assessed, given the lack of data on the nature of substrate at the LGM, including on the exposed sea floor. The GDM was then applied to create transformed environmental layers for each environmental variable included in the model, for the past, present and future climate scenarios. This then enables the prediction of plant community compositional similarity (the complement of dissimilarity) for any pair of grid cells over space and time, as described by Ferrier et al. (2007). Given the temporal nature of our subsequent analyses, only the environmental variables in our GDM were utilized to predict compositional similarity, with geographical distance (the weakest predictor variable) being excluded.

\section{Refugia analyses}

We assessed past, present and future refugia relevant to the palaeoendemic flora of Tasmania, where palaeoendemism for a clade (a species or monophyletic group of species) is quantified as the age of the clade divided by the square root of its area of occurrence (Jordan et al., 2016). Spatially explicit data on current levels of palaeoendemism for 1189 grid cells (30" or c. $1 \mathrm{~km}$ resolution) across Tasmania were obtained from Jordan et al. (2016), who summed the palaeoendemism scores for all high-scoring $\left(>200\right.$ year $\mathrm{m}^{-1}$ ) clades present in each $1 \mathrm{~km}$ grid cell. Of the 33 high scoring palaeoendemic plant species in Tasmania (see Appendix S2), the highest scoring species were coniferous alpine trees and shrubs, such as drooping pine (Pherosphaera hookeriana), creeping pine (Microcachrys tetragona), and pencil pine (Athrotaxis cupressoides).

We cube transformed these community-level palaeoendemism scores from Jordan et al. (2015) and normalized them to range from 0 to 1 , in order to account for the positively skewed distribution of palaeoendemism scores (small number of high scores). The $250 \mathrm{~m}$ grid cell at the centroid of each $1 \mathrm{~km}$ grid cell from Jordan et al. (2015) was used as the reference point for further analyses. The projected GDM was then applied to calculate the mean pairwise compositional similarity $\left(\bar{S}_{i}\right)$ of each grid cell $i$ across Tasmania (in either, past, present or future climate), to the $n=1189$ grid 
cells $j$ with palaeoendemism scores (under present climate), weighted by their relative palaeoendemism score $\left(P_{j}\right)$ :

$$
\bar{S}_{i}=\frac{\sum_{j=1}^{n} P_{j} \cdot S_{i j}}{\sum_{j=1}^{n} P_{j}}
$$

where the predicted compositional similarity between a pair of grid cells $i$ and $j\left(S_{i j}\right)$ is obtained by summing the absolute difference in their GDM transformed environmental values $\left(f_{k}\left(x_{k}\right)\right)$, across all $L$ environmental variables included in the GDM (Ferrier et al., 2007):

$$
S_{i j}=e^{-\sum_{k=1}^{L}\left|f_{k}\left(x_{k i}\right)-f_{k}\left(x_{k j}\right)\right|}
$$

To identify areas that have high spatiotemporal connectivity in terms of their capacity to support the Tasmanian palaeoendemic flora over past, present and future climates, we derived a new spatiotemporal connectivity index $\left(C_{i Q}\right)$ :

$$
C_{i Q}=\min _{q \in Q}\left(N_{i q}\right)
$$

For each grid cell $i$, the spatiotemporal connectivity index $\left(C_{i \mathrm{Q}}\right)$ represents the minimum of the neighbourhood weighted similarity to palaeoendemic scores $\left(N_{i q}\right)$, across all $Q$ climate scenarios (past, present, future). For a given climate scenario $q$, the neighbourhood weighted similarity to palaeoendemic scores $\left(N_{i q}\right)$ is derived as the mean pairwise compositional similarity to the palaeoendemic scores $\left(\bar{S}_{r}\right.$, from equation 1) for each grid cell $r$ within the circular neighbourhood of specified radius around the focal cell $i$ (and containing $R$ neighbouring cells in total), weighted by a factor $w_{r}$ based on the distance between the neighbouring cell and the focal cell $\left(d_{i r}\right)$ :

$$
N_{i q}=\frac{\sum_{r=1}^{R} w_{r} \cdot \overline{S_{r}}}{\sum_{r=1}^{R} w_{r}}
$$

where the weighted contribution of a neighbouring cell $\left(w_{r}\right)$ is derived from a Gaussian function centred on the focal cell (i), normalized to the weight of the focal cell $\left(w_{i}\right)$ :

$$
w_{r}=\frac{1}{w_{i}} \cdot \frac{1}{\sigma \sqrt{2 \pi}} e^{\frac{-d_{i r}}{2 \sigma^{2}}}
$$

Here, we applied a maximum radius of $3 \mathrm{~km}$ and a standard deviation $(\sigma)$ of $1 \mathrm{~km}$ in deriving the weighting for each cell in the circular neighbourhood.

\section{Validation analyses}

To assess the validity of our temporal projections of refugia for Tasmania's palaeoendemic flora, we harnessed fossil pollen data from the LGM for 12 sites across Tasmania (Colhoun \& Shimeld, 2012) (see Appendix S3). For each site, we created a summed palaeoendemism score, as in Jordan et al. (2016), based on the presence of pollen from all high scoring (>200 year $\left.\mathrm{m}^{-1}\right)$ palaeoendemic clades (see Table S2.1). These summed palaeoendemism scores for the 12 sites at the LGM were then compared to the predicted palaeoendemic refugia value $\left(\bar{S}_{i}\right)$ for those locations at the LGM from our GDM analyses, using simple linear regression (see Appendix S3).

\section{RESULTS}

The revised GDM developed for the Tasmanian flora explained $51.1 \%$ of the deviance in pairwise plant community compositional similarity, based on four environmental variables and geographical distance (see Table S1.1, Figs S1.1 \& S1.2). Harnessing the Tasmanian plant GDM, and the 1189 locations with palaeoendemism scores (see Fig. S2.1), we predicted the mean weighted similarity to the locations with palaeoendemism scores, for every grid cell across Tasmania, under past (LGM), current (2015) and future (2100) climates (Fig. 2). GDM predicted mean weighted similarity to the palaeoendemism scores for current climate were strongly related to the palaeoendemism scores in the 1189 reference locations $\left(R^{2}=0.62, P<0.001\right.$; see Fig. S2.2).

Current refugia predicted for Tasmania's palaeoendemic flora are similar to those areas of high density predicted by Jordan et al. (2015), being higher elevation, cool, wet environments (Fig. 2b). Predicted areas of refugia at the LGM for the palaeoendemic flora differ substantially between the two climate projections for this period, being focussed on low elevation habitats in the south-west for the cooler and more realistic CCSM model (Fig. 2a), and mid-elevation habitats across western Tasmania for the CNRM model (see Fig. S4.1B). In contrast, there was stronger agreement for predictions under the alternative GCMs for future climates (2100), with similar spatial distribution of palaeoendemic refugia to current areas at high elevation (Fig. 2c, see Fig. S4.1E), but with the highest predicted values of mean weighted similarity being markedly reduced [current $=0.54$; $2100($ MIROC $)=0.45 ; 2100($ CSIRO $)=0.40]$. The validation analysis for predicted areas of palaeoendemic refugia at the LGM showed that these values were strongly and positively $\left(r^{2}=0.70 ; \quad P<0.001\right)$ associated with palaeoendemism scores derived from fossil pollen at the LGM (see Fig. S3.1).

We assessed the consistency of likely refugia for the palaeoendemic flora over past, present and future climates, by assessing overlap in areas with the highest (top 5\%) mean similarity to palaeoendemism scores over time (the c. $3000 \mathrm{~km}^{2}$ with the highest values). Here, we applied the more realistic CCSM projection for the LGM (Worth et al., 2014), and the MIROC projection for 2100, given marginal differences between the CSIRO and MIROC GCMs in the top $5 \%$ predicted areas of palaeoendemic refugia. While there were large areas of overlap (85\%) in predicted current and future refugia for the palaeoendemic flora, there were only small areas of overlap $(0.7 \%)$ between LGM and current refugia (Fig. 3). The proportion of areas in the top 5\% of palaeoendemic refugia over past, present and future climates was very low $\left(0.3 \%\right.$ or c. $\left.9 \mathrm{~km}^{2}\right)$, occurring in 

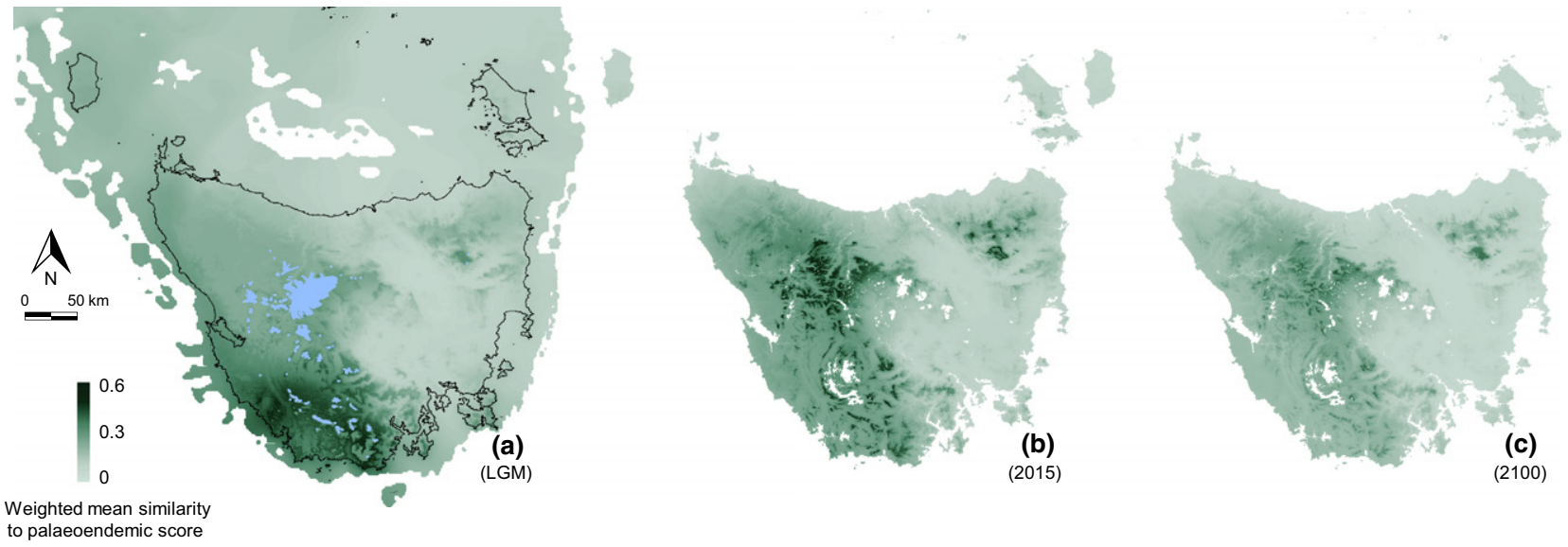

Figure 2 Predicted palaeoendemic refugia, quantified as the weighted mean similarity to current (2015) Tasmanian palaeoendemic scores $\left(\bar{S}_{i}\right)$, for the projected LGM climate under the CCSM model (a), the present climate (b), and the projected climate in 2100 under the MIROC GCM and A2 emission scenario (c). For the LGM (a), the current coastal outline is shown in black, with areas in blue representing predicted permanent ice cover during the LGM. All areas in white indicate areas of water (lakes \& ocean).

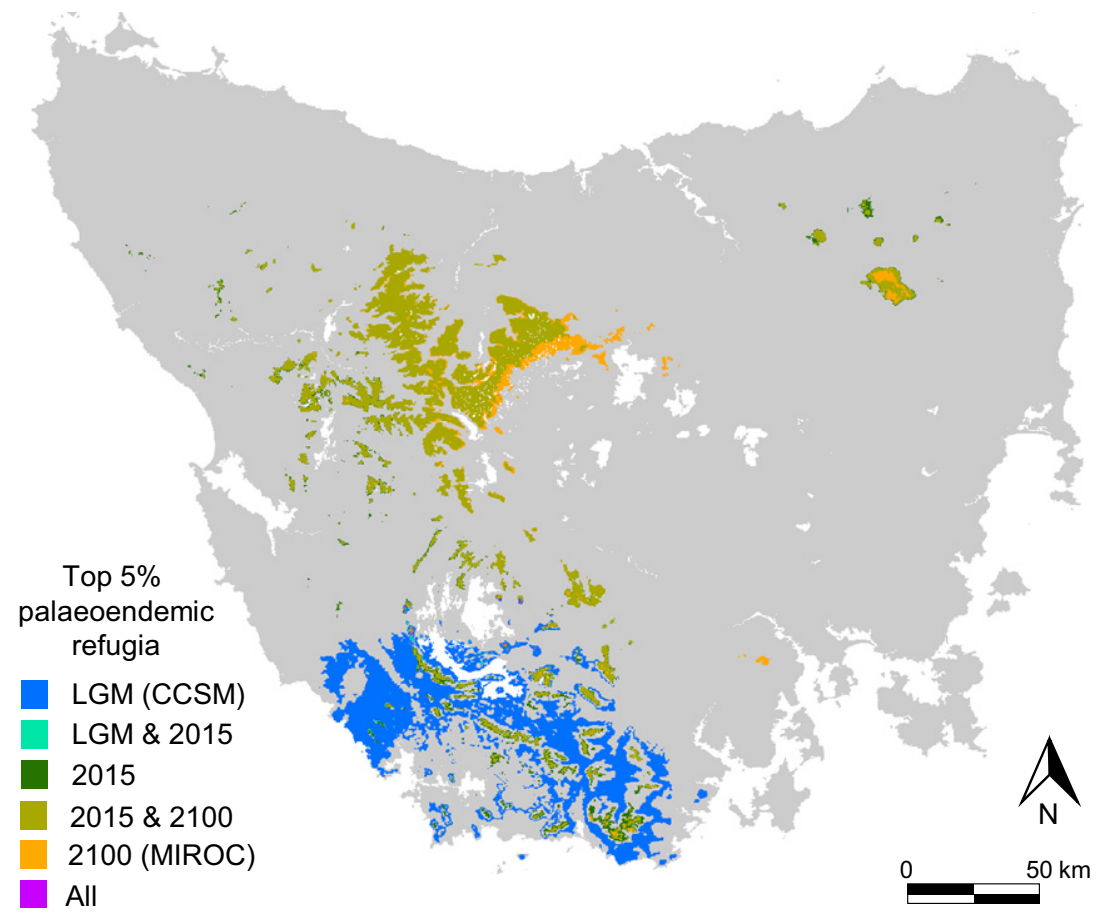

Figure 3 The distribution and overlap of areas with the highest (top 5\%) mean similarity to palaeoendemic score in the past [Last Glacial Maximum (LGM) - CCSM], present (2015), and future (2100 - MIROC) climates. Proportional overlap between time periods is: 0.007 between LGM \& 2015; 0.855 between 2015 \& 2100, and 0.003 between all three time periods (see also Fig. S4.3).

mid-elevation habitats on a number of mountain ranges in south-west Tasmania (e.g. Mt Wedge, Mt Anne) (Fig. 3, see Fig. S4.3).

Our analysis of areas that have high spatiotemporal connectivity in terms of their capacity to act as refugia for the Tasmanian palaeoendemic flora over past, present and future climates identified mountain ranges in central and southern Tasmania as being most connected to refugial environments (Fig. 4). The largest area with the highest spatiotemporal connectivity of palaeoendemic refugia was Mt Field, in central Tasmania.

\section{DISCUSSION}

Areas that are of consistently high value as refugia, regardless of major climatic fluctuations, are likely to be important in harbouring and retaining biodiversity over long periods of time. Places thought to be key refugia for species at the 


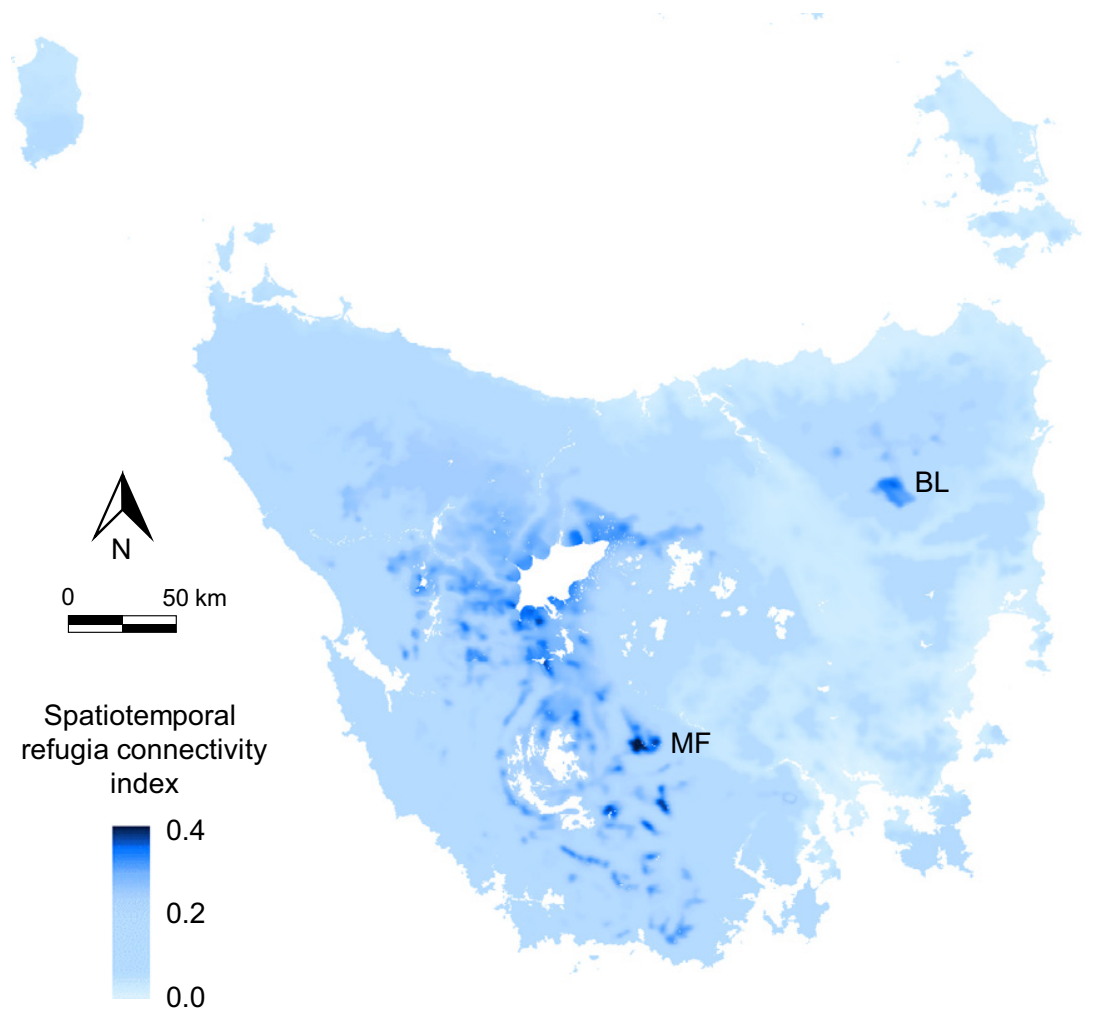

Figure 4 Predicted spatiotemporal connectivity of refugia for Tasmania's palaeoendemic flora $\left(C_{i \mathrm{Q}}\right)$, over projected past (CCSM, CNRM), present (2015) and future (MIROC, CSIRO) climates. $\mathrm{MF}=\mathrm{Mt}$ Field, $\mathrm{BL}=$ Ben Lomond.

LGM are commonly observed to support unique elements of diversity, including many species that are rare, endemic and have a unique phylogenetic heritage (Carnaval et al., 2009; Davies et al., 2009; Graham et al., 2010; Rosauer et al., 2015). Likewise, possible refugia under anthropogenic climate change may be important in retaining this unique diversity into the future (Keppel et al., 2012). Therefore, areas retaining high spatiotemporal connectivity to refugial environmental conditions, under past, present and future climates are likely to be critical for the long-term maintenance of biodiversity.

Consistently high value refugia may be especially important for sensitive groups of species, such as the palaeoendemic flora of Tasmania (Jordan et al., 2016). Palaeoendemic plant species in Tasmania are of high conservation value, given their restricted geographical ranges and ancient phylogenetic lineages. However, some of their shared physiological attributes pose a challenge for biodiversity managers, such as fire sensitivity, slow growth and remote occurrences (Jordan et al., 2016). Maintaining this unique element of biodiversity over the long term requires protection and management of those areas that retain a high stability and connectivity of suitable environmental conditions over space and time (wet, unburnt, cool summers, mild winters).

We quantified refugia for Tasmania's palaeoendemic flora using a new approach, based on community-level modelling of compositional turnover (GDM), and a set of reference locations scored for their current value for biodiversity. For any location in the past, present or future, we then obtained an estimate of its refugial potential $\left(\bar{S}_{i}\right)$ by determining the mean similarity of that location under that climate to the reference locations under the current climate, weighted by the 'biodiversity value' of those reference locations (here, the palaeoendemism scores). This communitylevel approach to refugia identification is particularly well suited to taxonomic groups that are species-rich, poorly studied or contain substantial numbers of rare species, where species-level approaches such as SDMs may be less suitable. Applying this approach to predict compositional similarity over time (to the LGM or 2100) relies on the commonly applied assumption of space for time substitution, and indeed there is good support that present-day responses of compositional turnover along environmental gradients observed through spatial patterns are relatively well maintained as environmental conditions change over time (Blois et al., 2013).

For Tasmania's palaeoendemic flora, our projections of current patterns in environmental suitability (Fig. 2b) closely match the observations (see Figs S2.1 and S2.2) and prior analyses (Jordan et al., 2016), supporting the validity of our general approach. In addition, our projections of palaeoendemic refugia at the LGM strongly align with observed community-level palaeoendemism scores, based on 12 sites across Tasmania for which there is a reliable record of fossil pollen 
(see Fig. S3.1). This result adds further support to the existing evidence suggesting a retreat of the palaeoendemic flora to lower elevation refugia at the LGM (Kirkpatrick, 1997; Colhoun \& Shimeld, 2012).

In terms of the key focus of our study, we show that for palaeoendemic plant species in Tasmania, there is little overlap in those areas identified as the highest value refugia over past, present \& future climates (Figs 2 \& 3, see Fig. S4.3). The lack of persistent refugia for Tasmania's palaeoendemic plants was primarily due to the areas of highest projected refugia value under the LGM being spatially disjunct from the refugia in either current or future climates (Figs $2 \& 3$ ). Consequently, the few areas that were predicted as persistent refugia over the three climates were in the lower elevational range (700-1000 $\mathrm{m}$ a.s.l.) and warmer temperature range (6$8{ }^{\circ} \mathrm{C}$ annual mean) of the current locations of highest palaeoendemic plant refugia value (see Figs S6 and S7). There was, however, high overlap (c. 85\%) between the current climate and likely warmer future under climate change in projected refugia for Tasmania's palaeoendemic flora (Figs 2 \& 3).

It is clear, however, that simple measures of refugia persistence ignore the potential for dispersal and range shifts over time. Here, we accounted for this through a new index of refugia spatiotemporal connectivity $\left(C_{i \mathrm{Q}}\right)$, which incorporates the amount and configuration of continuously varying refugia values, through a non-linear distance weighting. Quantifying connectivity in refugia over the past, present and future highlights areas likely to be important regardless of the directionality of changes in climate. Our refugia connectivity analyses highlight a number of important areas for Tasmania's palaeoendemic flora, especially Mt Field National Park in central Tasmania (Fig. 4). Hence, not only is Mt Field an important current refuge for many palaeoendemic plant species (Jordan et al., 2016), but it is likely to retain high connectivity to refugial environments under both cooler and warmer climates (Figs $3 \& 4$ ). The high spatiotemporal refugia connectivity of $\mathrm{Mt}$ Field could indeed contribute to its current high palaeoendemism scores, compared to other areas with similar environments.

While our analyses largely concord with existing knowledge of Tasmania's palaeoendemic flora (Kirkpatrick \& Brown, 1984; Jordan et al., 2016), this is not the case for Ben Lomond National Park in Tasmania's north-east (Fig. 4). At Ben Lomond, we predict relatively high current refugia value for the palaeoendemic flora (Fig. 2b) and moderately high spatiotemporal connectivity in palaeoendemic refugial environments (Figs 3 \& 4), despite this area currently possessing relatively low observed palaeoendemism scores (see Fig. S2.1). This disjunct between prediction and observation might be explained by the relatively isolated location of Ben Lomond from the main area of palaeoendemic refugial environments in western Tasmania, combined with potential periods of less suitable climates during times not assessed by our analyses (e.g. a previous glacial maximum that may have been much drier).
Our projections of areas of persistence (Fig. 3) and spatiotemporal connectivity (Fig. 4) of refugia for Tasmania's palaeoendemic flora can also help inform the conservation and management of these species. While most areas of high refugial value under current climate occur within protected areas, the management of these areas has a large role to play in promoting the persistence of the palaeoendemic flora. The greatest immediate threat to the palaeoendemic flora is wildfire (Kirkpatrick, 1997; Yospin et al., 2015; Jordan et al., 2016), and much can be done to reduce the risk of large fires spreading into these sensitive environments. In particular, fire management focus is warranted for the large areas of high spatiotemporal connectivity in refugial environments, such as Mt Field and Mt Anne (Fig. 4). Climate change is likely to increase the risk of large wildfires in Tasmania (Fox-Hughes et al., 2014) and facilitate fire-adapted plant species from lower elevations migrating upslope and displacing palaeoendemics (Kirkpatrick, 1997; Holz et al., 2015). Increased risk of pathogens and disease is also likely, including the upward spread of the root-rot fungus Phytophthora cinnamomi into sites that are currently too cold or too dry for disease-causing activity (Podger et al., 1990).

While our projections of broad-scale reduction in palaeoendemic refugia quality under climate change (Fig. 2, see Fig. S4.1) indicate that mitigating climate change will have a major impact on promoting the persistence of these species (Warren et al., 2013), conservation management has a strong role to play in ameliorating some of the consequences of climate change. Improved planning and finer scale on-ground management responses could be identified and implemented to reduce the risk of fire and biosecurity incursions under future climate change, as well as managing non-climate pressures that impact on palaeoendemic species. A number of adaptation actions have been identified for alpine and rain forest environments rich in palaeoendemic plant species at the site and landscape scale and for immediate and longer term time-scales (Gilfedder et al., 2012). Recent experience with wildfires in January 2016 in these environments demonstrates the urgency for future planning of management responses to protect important refugia for palaeoendemic plant species (Rickards, 2016).

Although our study has demonstrated new approaches to quantifying refugia quality and spatiotemporal connectivity, future research could further advance our capacity to identify key refugia for biodiversity, to better inform conservation and management. A major limitation encountered in this study was the availability of reliable fine spatial resolution climate projections for past climates, akin to those currently available for future climates in Tasmania (Corney et al., 2010; Grose et al., 2010). Greater effort is required by climate scientists and ecologists to improve the range of climate models and the methods used to downscale them, if we are to better quantify spatiotemporal connectivity of refugia at ecologically meaningful spatial resolutions (10s to 100 s of metres). Reliable fine-resolution palaeoclimate projections would also enable the application of more dynamic semi- 
mechanistic biodiversity models to assess refugia potential over time (Mokany et al., 2012; Keppel et al., 2015), to complement the correlative approach we applied here. Other advances to the present analysis could directly incorporate fire likelihood as a climate-derived secondary predictor variable of community compositional similarity, as well as improved fine-resolution soil layers (Viscarra Rossel et al., 2015).

In conclusion, the community-level approach to quantifying refugia presented here has the potential to advance consideration of refugia for taxonomic groups involving large numbers of species, poorly studied species or many rare species. For the palaeoendemic flora of Tasmania, our new approaches identified likely areas of refugia under past, present and future climates, with a number of important areas of high spatiotemporal connectivity identified, despite the dearth of locations acting as refugia over all three time points considered. Projections made from these novel analytical approaches have the potential to improve our understanding of biodiversity dynamics and identify priorities for conservation and management of important biodiversity features.

\section{REFERENCES}

Ashcroft, M.B. (2010) Identifying refugia from climate change. Journal of Biogeography, 37, 1407-1413.

Barrows, T.T., Stone, J.O., Fifield, L.K. \& Cresswell, R.G. (2002) The timing of the Last Glacial Maximum in Australia. Quaternary Science Reviews, 21, 159-173.

Bennett, K.D. \& Provan, J. (2008) What do we mean by 'refugia'? Quaternary Science Reviews, 27, 2449-2455.

Birks, H.J.B. (2015) Some reflections on the refugium concept and its terminology in historical biogeography, contemporary ecology and global-change biology. Biodiversity, 16, 196-212.

Blois, J.L., Williams, J.W., Fitzpatrick, M.C., Jackson, S.T. \& Ferrier, S. (2013) Space can substitute for time in predicting climate-change effects on biodiversity. Proceedings of the National Academy of Sciences USA, 110, 93749379.

Braconnot, P., Harrison, S.P., Kageyama, M., Bartlein, P.J., Masson-Delmotte, V., Abe-Ouchi, A., Otto-Bliesner, B. \& Zhao, Y. (2012) Evaluation of climate models using palaeoclimatic data. Nature Climate Change, 2, 417-424.

Carnaval, A.C., Hickerson, M.J., Haddad, C.F.B., Rodrigues, M.T. \& Moritz, C. (2009) Stability predicts genetic diversity in the Brazilian Atlantic forest hotspot. Science, 323, 785-789.

Colhoun, E.A. \& Shimeld, P.W. (2012) Late-Quaternary vegetation history of Tasmania from pollen records. Peopled landscapes: archaeological and biogeographic approaches to landscapes (ed. by S.G. Haberle and B. David), pp. 297328. ANU Press, Canberra.

Corney, S., Katzfey, J., McGregor, J., Grose, M., Bennett, J., White, C., Holz, G., Gaynor, S. \& Bindoff, N. (2010)
Climate futures for Tasmania: climate modelling technical report. Antarctic Climate \& Ecosystems Cooperative Research Centre, Hobart.

Davies, T.J., Purvis, A. \& Gittleman, J.L. (2009) Quaternary climate change and the geographic ranges of mammals. The American Naturalist, 174, 297-307.

Espíndola, A., Pellissier, L., Maiorano, L., Hordijk, W., Guisan, A. \& Alvarez, N. (2012) Predicting present and future intra-specific genetic structure through niche hindcasting across 24 millennia. Ecology Letters, 15, 649-657.

Ferrier, S., Manion, G., Elith, J. \& Richardson, K. (2007) Using generalized dissimilarity modelling to analyse and predict patterns of beta diversity in regional biodiversity assessment. Diversity and Distributions, 13, 252-264.

Fox-Hughes, P., Harris, R., Lee, G., Grose, M. \& Bindoff, N. (2014) Future fire danger climatology for Tasmania, Australia, using a dynamically downscaled regional climate model. International Journal of Wildland Fire, 23, 309-321.

Gavin, D.G., Fitzpatrick, M.C., Gugger, P.F. et al. (2014) Climate refugia: joint inference from fossil records, species distribution models and phylogeography. New Phytologist, 204, 37-54.

Gilfedder, L., Macgregor, N., Bridle, K., Carter, O. \& Sprod, D. (2012) Implementing adaption to climate change in terrestrial and freshwater natural environments in Tasmania. p. 61. Department of Primary Industries, Parks, Water \& Environment, Hobart.

Graham, C.H., VanDerWal, J., Phillips, S.J., Moritz, C. \& Williams, S.E. (2010) Dynamic refugia and species persistence: tracking spatial shifts in habitat through time. Ecography, 33, 1062-1069.

Grose, M., Barnes-Keoghan, I., Corney, S., White, C., Holz, G., Bennett, J., Gaynor, S. \& Bindoff, N. (2010) Climate futures for Tasmania: general climate impacts technical report. Antarctic Climate \& Ecosystems Cooperative Research Centre, Hobart.

Hampe, A. \& Jump, A.S. (2011) Climate relicts: past, present, future. Annual Review of Ecology, Evolution, and Systematics, 42, 313-333.

Hampe, A., Rodríguez-Sánchez, F., Dobrowski, S., Hu, F.S. \& Gavin, D.G. (2013) Climate refugia: from the Last Glacial Maximum to the twenty-first century. New Phytologist, 197, 16-18.

Holz, A., Wood, S.W., Veblen, T.T. \& Bowman, D.M.J.S. (2015) Effects of high-severity fire drove the population collapse of the subalpine Tasmanian endemic conifer Athrotaxis cupressoides. Global Change Biology, 21, 445458.

Jordan, G.J., Harrison, P.A., Worth, J.R.P., Williamson, G.J. \& Kirkpatrick, J.B. (2016) Palaeoendemic plants provide evidence for persistence of open, well-watered vegetation since the Cretaceous. Global Ecology and Biogeography, 25, 127-140.

Keppel, G., Van Niel, K.P., Wardell-Johnson, G.W., Yates, C.J., Byrne, M., Mucina, L., Schut, A.G.T., Hopper, S.D. \& Franklin, S.E. (2012) Refugia: identifying and understanding 
safe havens for biodiversity under climate change. Global Ecology and Biogeography, 21, 393-404.

Keppel, G., Mokany, K., Wardell-Johnson, G.W., Phillips, B.L., Welbergen, J.A. \& Reside, A.E. (2015) The capacity of refugia for conservation planning under climate change. Frontiers in Ecology and the Environment, 13, 106-112.

Kirkpatrick, J.B. (1997) Alpine Tasmania: an illustrated guide to the flora and vegetation. Oxford University Press, Melbourne.

Kirkpatrick, J.B. \& Brown, M.J. (1984) A numerical analysis of Tasmanian higher plant endemism. Botanical Journal of the Linnean Society, 88, 165-183.

Klein, C., Wilson, K., Watts, M., Stein, J., Berry, S., Carwardine, J., Smith, M.S., Mackey, B. \& Possingham, H. (2009) Incorporating ecological and evolutionary processes into continental-scale conservation planning. Ecological Applications, 19, 206-217.

Loarie, S.R., Carter, B.E., Hayhoe, K., McMahon, S., Moe, R., Knight, C.A. \& Ackerly, D.D. (2008) Climate change and the future of California's endemic flora. PLoS ONE, 3, e2502.

Maiorano, L., Cheddadi, R., Zimmermann, N.E., Pellissier, L., Petitpierre, B., Pottier, J., Laborde, H., Hurdu, B.I., Pearman, P.B., Psomas, A., Singarayer, J.S., Broennimann, O., Vittoz, P., Dubuis, A., Edwards, M.E., Binney, H.A. \& Guisan, A. (2013) Building the niche through time: using 13,000 years of data to predict the effects of climate change on three tree species in Europe. Global Ecology and Biogeography, 22, 302-317.

Manion, G., Lisk, M., Ferrier, S., Nieto-Lugilde, D. \& Fitzpatrick, M.C. (2016) gdm: Functions for Generalized Dissimilarity Modeling. $R$ package version 1.2.2.

Mokany, K., Harwood, T.D., Williams, K.J. \& Ferrier, S. (2012) Dynamic macroecology and the future for biodiversity. Global Change Biology, 18, 3149-3159.

Mokany, K., Thomson, J.J., Lynch, A.J.J., Jordan, G.J. \& Ferrier, S. (2015) Linking changes in community composition and function under climate change. Ecological Applications, 25, 2132-2141.

Pimm, S.L., Jenkins, C.N., Abell, R., Brooks, T.M., Gittleman, J.L., Joppa, L.N., Raven, P.H., Roberts, C.M. \& Sexton, J.O. (2014) The biodiversity of species and their rates of extinction, distribution, and protection. Science, 344, 987.

Podger, F.D., Mummery, D.C., Palzer, C. \& Brown, M.J. (1990) Bioclimatic analysis of distribution of damage to native plants caused by Phytophthora cinnamomi in Tasmania. Australian Journal of Ecology, 15, 281-289.

$\mathrm{R}$ Core Team (2016) R: A language and environment for statistical computing. $\mathrm{R}$ Foundation for Statistical Computing, Vienna, Austria.

Reside, A.E., Welbergen, J.A., Phillips, B.L., Wardell-Johnson, G.W., Keppel, G., Ferrier, S., Williams, S.E. \& VanDerWal, J. (2014) Characteristics of climate change refugia for Australian biodiversity. Austral Ecology, 39, 887-897.

Rickards, L. (2016) Goodbye Gondwana? Questioning disaster triage and fire resilience in Australia. Australian Geographer, 47, 127-137.
Rosauer, D.F., Catullo, R.A., VanDerWal, J., Moussalli, A. \& Moritz, C. (2015) Lineage range estimation method reveals fine-scale endemism linked to pleistocene stability in Australian rainforest herpetofauna. PLOS ONE, 10, e0126274.

Sørensen, T. (1948) A method of establishing groups of equal amplitude in plant sociology based on similarity of species and its application to analyses of the vegetation on Danish commons. Kongelige Danske Videnskabernes Selskab, 5, 1-34.

Terribile, L.C., Lima-Ribeiro, M.S., Araujo, M.B., Bizao, N., Collevatti, R.G., Dobrovolski, R., Franco, A.A., Guilhaumon, F., Lima, J.D., Murakami, D.M., Nabout, J.C., de Oliveira, G., de Oliveira, L.K., Rabelo, S.G., Rangel, T.F., Simon, L.M., Soares, T.N., Telles, M.P.D. \& Diniz, J.A.F. (2012) Areas of climate stability of species ranges in the Brazilian Cerrado: disentangling uncertainties through time. Natureza \& Conservacao, 10, 152-159.

Viscarra Rossel, R.A., Chen, C., Grundy, M.J., Searle, R., Clifford, D. \& Campbell, P.H. (2015) The Australian three-dimensional soil grid: Australia's contribution to the GlobalSoilMap project. Soil Research, 53, 845-864.

Warren, R., VanDerWal, J., Price, J., Welbergen, J.A., Atkinson, I., Ramirez-Villegas, J., Osborn, T.J., Jarvis, A., Shoo, L.P., Williams, S.E. \& Lowe, J. (2013) Quantifying the benefit of early climate change mitigation in avoiding biodiversity loss. Nature Climate Change, 3, 678-682.

Weber, L.C., VanDerWal, J., Schmidt, S., McDonald, W.J.F. \& Shoo, L.P. (2014) Patterns of rain forest plant endemism in subtropical Australia relate to stable mesic refugia and species dispersal limitations. Journal of Biogeography, 41, 222-238.

Worth, J.R.P., Williamson, G.J., Sakaguchi, S., Nevill, P.G. \& Jordan, G.J. (2014) Environmental niche modelling fails to predict Last Glacial Maximum refugia: niche shifts, microrefugia or incorrect palaeoclimate estimates? Global Ecology and Biogeography, 23, 1186-1197.

$\mathrm{Xu}, \mathrm{T}$. \& Hutchinson, M. (2010) ANUClim Version 6.1 User Guide. Fenner School of Environment and Society, The Australian National University, Canberra.

Yannic, G., Pellissier, L., Ortego, J. et al. (2014) Genetic diversity in caribou linked to past and future climate change. Nature Climate Change, 4, 132-137.

Yospin, G.I., Wood, S.W., Holz, A., Bowman, D.M.J.S., Keane, R.E. \& Whitlock, C. (2015) Modeling vegetation mosaics in sub-alpine Tasmania under various fire regimes. Modeling Earth Systems and Environment, 1, 1-10.

\section{SUPPORTING INFORMATION}

Additional Supporting Information may be found in the online version of this article:

Appendix S1 The generalized dissimilarity model for Tasmanian plants.

Appendix S2 Observed palaeoendemism scores for Tasmanian plants. 
Appendix S3 Validation of predicted palaeoendemic refugia for Tasmanian plants.

Appendix S4 Predicted palaeoendemic refugia for Tasmanian plants.

\section{BIOSKETCH}

Karel Mokany develops, tests and applies new macroecological modelling approaches to improve our understanding of biodiversity patterns and their likely change over time, as a basis for more informed policy, planning and management decisions.

Author contributions: K.M., G.J.J., G.K. and L.G. conceived the ideas; K.M., G.J.J., P.A.H. and O.C. collected and collated the data; K.M. and T.D.H. analysed the data; and K.M. led the writing, with all co-authors contributing.

Editor: Brian Huntley 